\title{
AUTOMATIC TYRE INFLATION SYSTEM IN DYNAMIC CONDITION
}

\author{
RAM BANSAL ${ }^{1}$, SHUBHAM SWAMI ${ }^{2}$, ALIASGERKANCHWALA ${ }^{3}$ \& MAZHARHUSSAIN ${ }^{4}$ \\ ${ }^{1}$ Assistant Professor, Mechanical Engineering Department, Medi-Caps University, Indore \\ ${ }^{2,3,4}$ Research Scholar, Automobile Engineering, Medi-Caps University, Indore
}

\begin{abstract}
In today's growing world, the possibilities of road accidents of any automobile are increasing at an alarming rate. The reasons for these happenings are the puncturing of tyres, when the vehicle is at very fast speeds due to any reason and because of that the driver loses his control over the vehicle.

Many studies have revealed that a drop in the tyre pressure by a few PSI results in the following:

- Reduction in the fuel economy

- Reduction of tyre life

- Reduces safety and performance of the vehicle

We have hence developed an automatic, self-inflating tyre system which will ensure that the tyres are properly inflated all the time. In our design, we have made the use of an air compressor that will store compressed air in an air tank at the desired pressure value which in turn will supply air to all the four tyres through hoses and rotary joint fixed between wheel hub and knuckle of each wheel. The use of rotary joint is to efficiently allow the air to be channelled to all the tyres without the tangling of hoses. With the current environmental issues and fast depletion of natural resources our project will successfully improve the overall fuel economy of the vehicle along with the increased tyre life and improved vehicle handling.

KEYWORDS: Tyre and Wheel Assembly, Rotary Joint, Compressor with Air Tank, Pressure Sensor Along with TPMS, Solenoid Valve \& Automation System (E. C. U programming)
\end{abstract}

Received: Nov 29, 2017; Accepted: Dec 18, 2017; Published: Jan 10, 2018; Paper Id.: IJAuERDFEB20181

\section{INTRODUCTION}

Under inflation of tyres is a common problem on the passenger cars. Surveys show that $80 \%$ of passenger vehicles running on the road have at least one under-inflated tyre and $36 \%$ of the cars have one tyre that is $20 \%$ or more under-inflated. The under inflation and over inflation of tyres is due to the following reasons:

- Pressure loss in tyre can be due to a small penetration of nail or due to natural permeation of air through the rubber. It can also be due to the road conditions such as potholes, etc.

- The rise in the pressure inside the tire is due to the expansion of the air inside the tyre due to its increased temperature while the vehicle is running continuously for long period of time.

Most of the car owners find it difficult to notice the under-inflation of the tyres as it is difficult to notice it visually as shown in figure 1 it is difficult to notice that a tyre is inflated properly or not; as a tyre that is properly inflated looks similar to that of either an over inflated or under inflated tyre. Thus, from the passenger perspective, 
they are losing their money due to increased tyre wear and reduced fuel efficiency. From the design point of view, one of the reasons being owner not knowing whether the tyre is underinflated or not: the other cause can also be the difficulty in finding the air pump on highways and lack of pressure measuring device. Hence the idea will benefit both the user as well as design point of view for the implementation of the model.
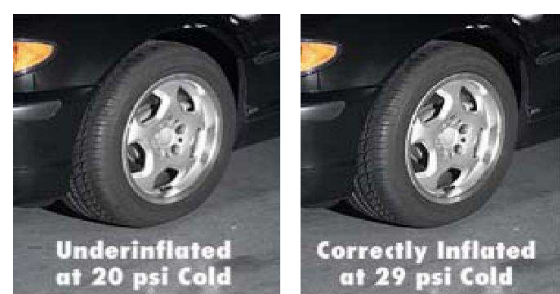

Figure 1: Difficult to Notice Under-Inflated tyre

\section{METHODOLOGY}

The idea will work as mentioned below, and will make use of various components the major of which dominate are:

- A wireless pressure sensor fitted inside the wheel rim of each tyre for sensing the air pressure inside the tyre continuously.

- Tyre pressure monitoring system (TPMS) which will continuously receive pressure value from the pressure sensor. This TPMS will be set at a certain value of high pressure as well as low pressure. As soon as either of the pressure value will be altered due to any reasons the TPMS will generate a signal in the form of buzzer sound which will in turn be an input to the ECU.

- An automation system programmed in such a manner that as soon as it will receive signal from the TPMS of either high or low pressure it will generate a current to actuate the compressor and solenoid valve. This will be done with the help of ECU programmed according to the logic mentioned in figure 2.

- An air compressor along with an air tank which will store the air at a predestined value of pressure in it. As soon as the signal will be passed by the ECU the solenoid valve will allow the air to pass through the air tank via the hoses or pressurized fluid linings.

- To prevent the hoses to be tangled and to provide the dynamic condition of the model we have used a rotary joint. The use of rotary joint is to channel the air inside each tyre coming from the solenoid valve without the tangling of hoses and also in the running condition of the vehicle.

The system will provide the owner with the following objectives:

\section{Ability to Provide Proper Tyre Pressure}

The first major objective of our research is to provide and adjust proper tyre pressures at each tyre on varying load and driving conditions. Specifically, it is desired that,

- The tyre pressure is maintained when the vehicle is running to account for slow leaks and varying tyre temperatures. 
- As vehicle speed increases or decreases the tyre pressure subsequently increase or decrease.

- As load on the vehicle increase or decrease the tyre pressure will increase or decrease respectively.

\section{Ability to Provide Automatic System}

The second objective is to provide the vehicle owner with an automatic system so that the user will not have to worry about the pressure increase or decrease in the tyre. The system will automatically inflate or deflate the tyre according to the low or high pressure inside the tyre. No human intervention will be required as all the work will be automatically done with the help of ECU and solenoid valve.

\section{COMPONENTS OF SETUP}

The logic for the purpose of automation is quite basic. We are using following components which will be interacting with each other during its working.

- $\quad \mathrm{ECU}$

- Air compressor

- $\quad$ Tyre pressure monitoring system

- Solenoid valves

Figure. 2 is a general flow chart of the logic steps that will be performed. As soon as the system will start the first thing that will be done is the sensing of the pressure of each tyre by the TPMS. As soon as it will receive any information of low or high pressure inside the tyre, it will generate a signal in the form of buzzer which will be the first input to the ECU. The ECU will in-turn gives a signal to open the solenoid valve and the air will flow through the air tank to the tyres until the pressure will be maintained to its desired value. As soon as the pressure value is achieved inside the tyre, the flow of air will be blocked.

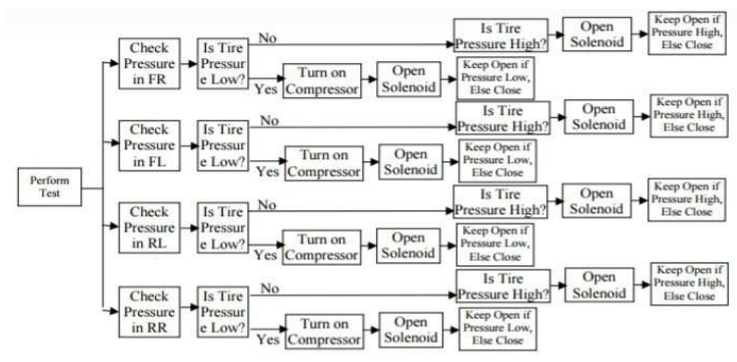

Figure 2: Flow Chart of Logic to be Performed for the Automation

Table 1: Specifications of Components

\begin{tabular}{|c|l|l|}
\hline S. No. & Name of Component & \multicolumn{1}{c|}{ Technical Specification } \\
\hline 1 & Air compressor & $300 \mathrm{psi}, 12$ volt \\
\hline 2 & Dc motor & $12 \mathrm{v} \mathrm{dc}$ at $6000 \mathrm{rpm}$ \\
\hline 3 & Pressure sensor & $0-100 \mathrm{psi}$ \\
\hline 4 & Rotary joint & Size: $1 / 2$ ", pressure $10 \mathrm{~kg} / \mathrm{cm}^{2}$ \\
\hline 5 & Hoses & Poly vinyl chloride $(\mathrm{pvc})$ \\
\hline 6 & Electronic control unit & - \\
\hline 7 & Tyre assembly & Pressed steel wheel with tubeless tyre \\
\hline 8 & Rigid axle & I-section \\
\hline
\end{tabular}




\section{DESIGN OF ROTARY JOINT}

\subsection{Vibration Analysis: Deflections Due to Resonance}

In performing the vibration analysis, one potential failure mode of the rotary joint system that was identified dealt with excessively large deflections of the CV joint shaft to which the rotary joint is attached. These large deflections would only occur if the angular velocity of the tyre (and hence CV joint shaft) matched the natural frequency of the rotary joint and shaft system, or more specifically, if

$$
\omega_{\mathrm{n}}=\omega_{\mathrm{tyre}}
$$

Where $\omega_{\mathrm{n}}$ is the natural frequency of the rotary joint-shaft system and $\omega_{\text {tyre }}$ is the angular velocity at which the tyre is operating. The condition that leads to large shaft deflections is known as resonance, and if this occurs, catastrophic failure due to shear is likely. In order to alleviate this problem, the natural frequency of the system (also known as the critical speed) should always be significantly above the angular velocity of the tyre, or more specifically,

$$
\omega_{\text {critc }}>\omega_{\text {tyre }}
$$

Where $\omega_{\text {critc }}$ is the critical speed of the rotary joint shaft-system and $\omega_{\text {tyre }}$ represents the same quantity previously mentioned. This design problem has been modelled based on the following assumptions:

- The CV joint shaft can be considered as a solid steel cylinder with a diameter of $132 \mathrm{~mm}$. a thickness of $32 \mathrm{~mm}$.

- Only half of the rotary joint (the portion located on the CV joint shaft) rotates; the other half, which is attached to the spindle at the base of a vehicle's strut, is stationary

- The rotating portion of the rotary joint can be modelled as a Mild steel "rotating disk" with initial dimensions as indicated in Table 2

- The vehicle (and hence tyre) speeds cannot exceed $150 \mathrm{mph}$, which corresponds to the "worst case" design scenario

- The tyres can be modelled as P205/65/15 grade as used on the Toyota Camry

The procedure of this analysis can therefore be summarized as the following:

- Determine the maximum angular velocity of the tyre

- Determine the critical speed of the rotary joint shaft system

- Compare the critical speed with the maximum angular velocity

If the critical speed exceeds the maximum angular velocity, then the design criterion is satisfied. If the critical speed is less than the maximum angular velocity, then the dimensions of the rotary joint must be changed such that the critical speed exceeds the maximum angular velocity. [7]

The first item needed to calculate the angular velocity of the tyre is the radius of the tyre. Knowing the grade of the tyre for this application, the radius can simply be found by

$$
\mathrm{r}_{\mathrm{tyre}}=0.65 \mathrm{w}_{\mathrm{tyre}}+\frac{1}{2} \mathrm{~d}_{\mathrm{rim}}
$$


Where $\mathrm{w}_{\text {tyre }}$ refers to the width of the tyre in inches, $\mathrm{d}_{\text {rim }}$ refers to the diameter of the rim in inches, and $\mathrm{r}_{\text {tyre }}$ refers to the radius of the tyre in inches. Note that the coefficient of the $\mathrm{w}_{\text {tyre }}$ term is merely the aspect ratio relating of the height and width of the tyre, which is stated in the tyre grade. With $\mathrm{w}_{\mathrm{tyre}}=205 \mathrm{~mm}$ and $\mathrm{d}_{\mathrm{rim}}=15 \mathrm{in}$, the radius of the tyre is

$$
\begin{aligned}
& \mathrm{r}_{\mathrm{tyre}}=0.65(205 \mathrm{~mm}) \times\left(\frac{1 \text { inch }}{25.4 \mathrm{~mm}}\right)+\frac{1}{2}(15 \mathrm{inch}) \\
& \mathrm{r}_{\mathrm{tyre}}=12.75 \text { inch }
\end{aligned}
$$

The angular velocity of the tyre is then expressed as the following:

$$
\omega_{\text {tyre }}=\frac{V_{\text {tire }}}{\gamma_{\text {tire }}}
$$

Where $\mathrm{V}_{\text {tyre }}$ is the velocity of the tyre in $\mathrm{mph}, \mathrm{r}_{\mathrm{tyre}}$ is the radius of the tyre in inches, and $\omega_{\text {tyre }}$ is the angular velocity of the tyre in rpm. With $\mathrm{V}_{\mathrm{tyre}}=150 \mathrm{mph}$ and $\mathrm{r}_{\mathrm{tyre}}=12.75 \mathrm{in}$, the angular velocity of the tyre is:

$$
\begin{aligned}
& \omega_{\mathrm{tyre}}=\frac{150(\mathrm{mph}) \times \frac{5280 f t}{\mathrm{mtle}} \times \frac{12 i n c h}{f t} \times \frac{1 h r}{60 m i n}}{12.75 i n c h} \times\left(\frac{1 \mathrm{rev}}{2 \pi r a d}\right) \\
& \omega_{\mathrm{tyre}}=1977.88 \text { r.p. m }
\end{aligned}
$$

In determining the critical speed of the rotary joint-shaft system, the first step is to determine the stiffness of the shaft. This quantity can be found by

$$
\mathrm{k}=\frac{E A_{\text {shaft }}}{l_{\text {shaft }}}
$$

Where $\mathrm{E}$ is the elastic modulus of the shaft in kpsi, $\mathrm{A}_{\text {shaft }}$ is the cross-sectional area of the shaft in in ${ }^{2}, 1_{\text {shaft }}$ is the length of the shaft in inches, and $\mathrm{k}$ is the stiffness of the shaft in $1 \mathrm{bf} / \mathrm{in}$. With $\mathrm{E}=30,000 \mathrm{kpsi}$ and $1_{\text {shaft }}=18$ in, the stiffness of the shaft is

$$
\begin{aligned}
& \mathrm{k}=\frac{(3000 p s t)\left(\frac{1000 p s i}{1 k p s i}\right)\left(\frac{\pi}{4}\right)\left(0.75^{2}\right)}{1 \text { inch }} \\
& \mathrm{k}=7.36 \times 10^{5} \frac{\mathrm{blf}}{\text { tnch }}
\end{aligned}
$$

The next phase is to calculate the mass of the rotating portion of the rotary joint according to the equation

$$
\mathrm{m}=\frac{\rho V_{\text {disk }}}{g}
$$

Where $\rho$ is the density of the disk in $l b f / i^{3}, V_{\text {disk }}$ is the initial volume of the disk in $\mathrm{in}^{3}, \mathrm{~g}$ is the gravitational acceleration in $\mathrm{ft} / \mathrm{s}^{2}$, and $\mathrm{m}$ is the mass of the disk in $\mathrm{lbf} \cdot \mathrm{s}^{2} / \mathrm{ft}$. With $\rho=0.098 \mathrm{lbf} / \mathrm{in}^{3}$, the mass of the disk is

$$
\begin{aligned}
& \mathrm{m}=\frac{\left(0.098 \frac{\pi b f}{n n^{8}}\right)\left(6.9 \mathrm{~m}^{2}\right)}{32.2 \frac{f t}{s^{2}}} \\
& \mathrm{~m}=0.02 \frac{\mathrm{bb} \times \mathrm{s}^{2}}{f t}
\end{aligned}
$$

Finally, the critical speed of the rotary joint-shaft system can be determined by 


$$
\begin{aligned}
& \omega_{\text {cric }}=\sqrt{\frac{k}{m}} \\
& \omega_{\text {cric }}=195883.70 \mathrm{rpm}
\end{aligned}
$$

Because the critical speed is on the order of 100 times greater than the maximum angular velocity of the shaft, it can be stated that the rotary joint-shaft system is more than sufficiently stable. An optimization on this to reduce the critical speed from an apparent "over-design" situation is made possible by increasing the mass via increasing the overall size of the rotary joint.

\subsection{Fabrication of Rotary Joint}

\subsubsection{Design Details}
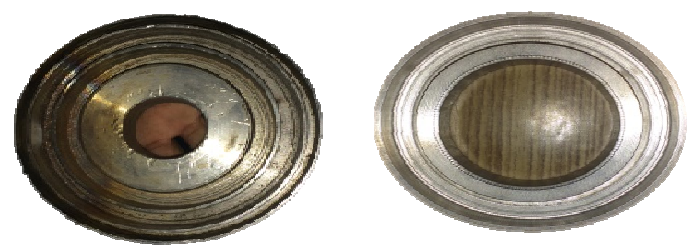

\section{Rotating Hub-Side Stationary Spindle-Side}

Figure 3: Rotary Joint CAD Model

The main criteria for our rotary joint design were the following:

- Must have a 40mm hole in the centre to allow for the axle to either pass through or support joint.

Air inlets and outlets must be located at the outer radius to allow the hoses on the outside of the joint to clear the vehicle spindle and hub.

Overall thickness of the joint must be no greater than $32 \mathrm{~mm}$ to so as not to interfere with the vehicle driveline or suspension components.

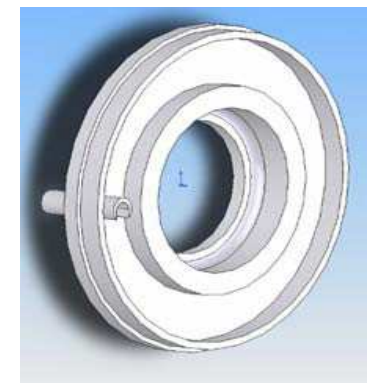

Rotating Hub-Side

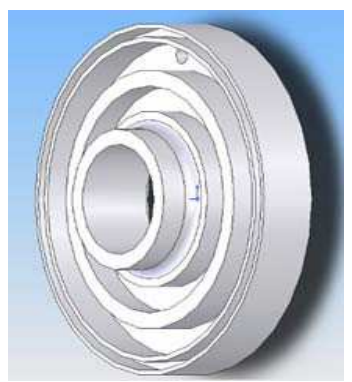

Stationary Spindle-Side

Figure 4: Machined Mild Steel Rotary Join

This design incorporates a $40 \mathrm{~mm}$ bore in the centre that allows the rotating half to completely rest on the drive axle while the stationary side rests above it and does not contact the rotating axle at all. It is also exactly $32 \mathrm{~mm}$ in thickness and $132 \mathrm{~mm}$ in diameter.

It is important to note that the air chamber is not designed to be completely air tight. Pressure losses across the rotary joint are expected and we will size the rest of our system (compressor, hoses, valves, etc.) to take this into account. 
By creating these joints in such a precise fashion, we were able to inspect and conclude that our rotary joint will be able to channel air through the "stationary" half of the rotary joint and out of the half thatrevolves with the wheel hub.

\subsubsection{Rotary Joint Design Optimization}

Since the rotary joint is the key component of our design's success, we set out to optimize the trade-off between minimizing area for air leakage from the perimeters of the rotary joint (both along the interior and exterior perimeters), minimizing rotary joint side-wall plate thickness, and maximizing the rotary joint mass (volume) to eliminate apparent over-design in shaft deflection (vibration). Specifically, Microsoft Excel Solver is used to optimize the design trade off that occurs when increasing mass increases wall thickness and increases the radius of the rotary joint [7].

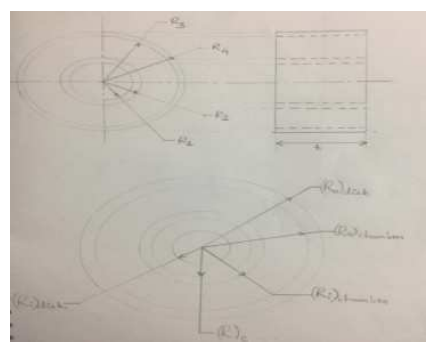

Figure 5: Nomenclature of Rotary Joint

Here,

$\left(r_{o}\right)_{\text {disk: }}$ :radius of outer disk

$\left(\mathrm{r}_{\mathrm{i}}\right)_{\text {disk}}:$ radius of inner disk

$\left(r_{o}\right)_{\text {chamber }}$ : radius of outer chamber

$\left(\mathrm{r}_{\mathrm{i}}\right)_{\text {chamber: }}$ : radius of inner chamber

$r_{c}$ : radius of couple

t: thickness of disk

$h$ : thickness of groove between $R_{c} \&\left(R_{i}\right)_{\text {disk }}$

$d_{\text {disk: }}$ : thickness of groove between $R_{1}, R_{2}, R_{3}, R_{4}$

$R_{1}, R_{2}, R_{3}, R_{4}$ : radius for optimization

$\tau_{\mathrm{y}}$ : yield stress of material for rotary joint

$\mathrm{S}_{\mathrm{f}}$ : factor of safety

P: pressure inside rotary joint

The objective for the rotary joint design optimization is to minimize the below equation:

(A)leakage $+(\mathrm{t})$ rotary joint wall $+\frac{1}{V_{\text {rotary joint plates }}}$

Where,

$(\mathrm{V})_{\text {roraty joint plates }}=\pi\left\{\left(\mathrm{r}_{\mathrm{o}}\right)_{\text {disk }}{ }^{2}-\left(\mathrm{r}_{\mathrm{i}}\right)_{\text {disk }}{ }^{2}\right\} \mathrm{t}-\pi\left[\left(\mathrm{R}_{2}{ }^{2}-\mathrm{R}_{1}{ }^{2}\right)+\left(\mathrm{R}_{4}{ }^{2}-\mathrm{R}_{3}{ }^{2}\right)\right] \mathrm{d}_{\text {disk }}+\pi\left\{\mathrm{r}_{\mathrm{c}}{ }^{2}-\left(\mathrm{r}_{\mathrm{i}}\right)_{\text {disk }}{ }^{2}\right\} \mathrm{h}+\pi\left\{\left(\mathrm{r}_{\mathrm{o}}\right)_{\text {chamber }}{ }^{2}-\left(\mathrm{r}_{\mathrm{i}}\right)_{\text {chamber }}{ }^{2}\right\} \mathrm{d}_{\text {disk }}=$ 
$\pi\left[\left\{\left(\mathrm{r}_{\mathrm{o}}\right)_{\text {disk }}{ }^{2}-\left(\mathrm{r}_{\mathrm{i}}\right)_{\text {disk }}{ }^{2}\right\} \mathrm{t}-\left\{\left(\mathrm{R}_{2}{ }^{2}-\mathrm{R}_{1}{ }^{2}\right)+\left(\mathrm{R}_{4}{ }^{2}-\mathrm{R}_{3}{ }^{2}\right)+\left(\mathrm{r}_{\mathrm{o}}\right)_{\text {chamber }}{ }^{2}-\left(\mathrm{r}_{\mathrm{i}}\right)_{\text {chamber }}{ }^{2}\right\} \mathrm{d}_{\text {disk }}+\left\{\mathrm{r}_{\mathrm{c}}{ }^{2}-\left(\mathrm{r}_{\mathrm{i}}\right)_{\text {disk }}{ }^{2}\right\} \mathrm{h}\right]$

$(\mathrm{A})_{\text {leakage }}=\frac{\left(2 \pi \mathrm{R}_{1}+2 \pi \mathrm{R}_{\mathrm{g}}\right)\left[\tau_{y} \pi\left(R_{4}^{2}-R_{\mathrm{g}}^{z}\right)\right]}{\left[P\left(2 \pi \mathrm{R}_{\mathrm{g}}\right)\right]}$

$\&$

$(\mathrm{t})_{\text {rotary joint wall }}=\frac{s_{f}\left[P\left(\pi R_{3}^{2}-\pi R_{2}^{2}\right)\right]}{\tau_{y}\left(2 \pi R_{3}+2 \pi R_{2}\right)}$

\section{EXPERIMENTAL SETUP}

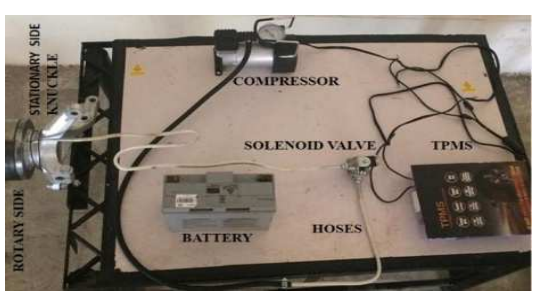

Figure 6: Experimental Setup

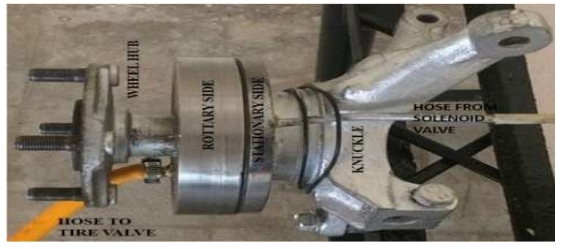

Figure 7: Rotary Joint, Wheel Hub and Knuckle

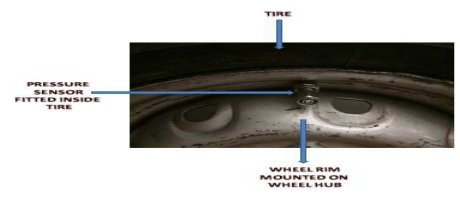

Figure 8: Tyre with Pressure Sensor

\section{RESULT AND CONCLUSIONS}

Table 2: Values of Variables used for Rotary Joint

\begin{tabular}{|c|c|c|c|}
\hline S No. & Variables Used & Value & Unit \\
\hline 1 & $\mathrm{r}_{\mathrm{o} \text { disk }}$ & 2.46 & inch \\
\hline 2 & $\mathrm{r}_{\mathrm{i}, \text { disk }}$ & 0.77 & inch \\
\hline 3 & $\mathrm{r}_{\mathrm{o} \text { hamber }}$ & 2.20 & inch \\
\hline 4 & $\mathrm{r}_{\mathrm{i}, \text { chamber }}$ & 1.81 & inch \\
\hline 5 & $\mathrm{r}_{\text {couple }}$ & 1.07 & inch \\
\hline 6 & $\mathrm{t}$ & 0.591 & inch \\
\hline 7 & $\mathrm{~d}_{\text {disk }}$ & 0.394 & inch \\
\hline 8 & $\mathrm{~h}$ & 0.394 & inch \\
\hline 9 & $\mathrm{r}_{1}$ & 1.23 & inch \\
\hline 10 & $\mathrm{r}_{2}$ & 1.58 & inch \\
\hline 11 & $\mathrm{r}_{3}$ & 2.27 & inch \\
\hline 12 & $\mathrm{r}_{4}$ & 2.40 & inch \\
\hline 13 & $\mathrm{~V}_{\text {disk }}$ & 6.9 & inch \\
\hline 14 & $\mathrm{~m}$ & 0.02 & lbf* $^{2} / \mathrm{ft}^{3}$ \\
\hline
\end{tabular}


Table 4: Results

\begin{tabular}{|c|c|c|c|}
\hline S No. & $\begin{array}{c}\text { Variable To Be } \\
\text { Determined }\end{array}$ & $\begin{array}{c}\text { Value of } \\
\text { Variable }\end{array}$ & Unit \\
\hline 1 & & & \\
\hline 2 & & & \\
\hline 3 & & & $\mathrm{rpm}$ \\
\hline 4 & $\omega_{\text {cric }}$ & 195883.70 & $\mathrm{mph}$ \\
\hline 5 & $\mathrm{~V}_{\text {tyre }}$ & 150 & $\mathrm{~mm}$ \\
\hline 6 & $\mathrm{w}_{\mathrm{tyre}}$ & 205 & $\mathrm{inch}$ \\
\hline 7 & $\mathrm{~d}_{\mathrm{rim}}$ & 15 & $\mathrm{inch}$ \\
\hline 8 & $\mathrm{r}_{\mathrm{tyre}}$ & 15.75 & $\mathrm{rpm}$ \\
\hline 9 & $\omega_{\text {tyre }}$ & 1977.88 & \\
\hline
\end{tabular}

The dynamically-self-inflating tyre system would be capable of succeeding as a new product in the automotive supplier industry. It specifically addresses the needs of the consumers by maintaining appropriate tyre pressure conditions for:

- $\quad$ Reduced tyre wear

- Increased fuel economy

- Increased overall vehicle safety

Because such a product does not currently exist for the majority of passenger vehicles, the market conditions would be favourable for the introduction of a self-inflating tyre system.

\section{REFERENCES}

1. Indrajeet Singh, Student, Department of Mechanical Engineering, R. S. R. Rungta College of Engineering \&Technology, Bhilai “To Study on Implementation of Tyre Inflation System for Automotive Vehicles.”International Journal of Innovative Research in Science, Engineering and Technology, Vol. 5, Issue 4, (An ISO 3297: 2007 Certified Organization), April 2016.

2. AdershVinayak, Professor, Department of Electronics and Communication Engineering, Matha College of Technology, M. G University, Kerala “Tyre Pressure Monitoring and Automatic Air Filling System.”International Journal of Research in Engineering \& Advanced Technology, Volume 2, Issue 2, Apr-May, 2014.

3. P. Ramanjaneyulu \& V. C. Veera Reddy, A Novel Bacterial Foraging Optimization Approach (BFOA) for Optimal Placement of Facts Devices to Enhance ATC under Dynamic Conditions, International Journal of Electrical and Electronics Engineering Research (IJEEER), Volume 4, Issue 4, July - August 2014, pp. 157-164

4. HarshalJunankar, Student and Chetal Gupta, Associate Professor, Department of Mechanical Engineering, Priyadarshini College of Engineering, Nagpur, “|A Review: Automatic Tyre Inflation System.” International Journal for Scientific Research \& Development Vol. 3, Issue 01, 2015.

5. Crouse Anglin “Automotive Mechanics”, Tata McGraw Hills.

6. www.howstuffworks.com

7. www.cycloid.com

8. PanosPapalambros, Professor, Department of Mechanical Engineering, University of Michigan, "Dynamically-Self-Inflating Tyre System. 
